\title{
ÉTICA DEL DESARROLLO, DEMOCRACIA DELIBERATIVA Y CIUDADANÍA AMBIENTAL. EL DESAFÍO GLOBAL DE LA SUSTENTABILIDAD ${ }^{1}$
}

\author{
Raúl Villarroel \\ Universidad de Chile \\ rvillarr@uchile.cl
}

\begin{abstract}
Resumen / Abstract
El artículo busca profundizar en el examen de la noción de "ciudadanía" a partir del contexto teórico desplegado por la problemática ecológica, teniendo en cuenta las determinaciones y desafíos que impone a la figura de la ciudadanía la supuesta existencia de un fenómeno de devastación antropogénica como el que se sostiene que afecta al planeta en nuestros días. Se intenta esbozar algunas consideraciones que permitan el avance de una reflexión particular sobre "ciudadanía ambiental", asumiendo que la literatura filosófico-política contemporánea presenta variados alcances teóricos que podrían ser atendidos en este sentido, puesto que ellos también buscan ampliar el concepto canónico de ciudadanía presentado inicialmente por Marshall.
\end{abstract}

Palabras clave: ciudadanía ambiental, ciudadanía, medio ambiente, ética del desarrollo, democracia deliberativa.

DEVELOPMENT ETHICS, DELIBERATIVE DEMOCRACY AND ENVIRONMENTAL CITIZENSHIP. THE GLOBAL CHALLENGE OF SUSTAINABILITY

This paper explores the notion of "citizenship" from a theoretical context showed by ecological problems, in order to face challenges posed by the alleged existence of an environmental anthropogenic devastation phenomenon that would be affecting our planet in nowadays. Some remarks about "environmental citizenship" are outlined, assuming the contemporary political philosophical point of view, since it extends the canonical concept of citizenship initially presented by Marshall.

KEY WORDS: Environmental citizenship, Citizenship, Environment, Development ethics, Deliberative democracy.

Este artículo se deriva de la investigación asociada al Proyecto Fondecyt No 1120141 "La articulación entre éticas del desarrollo y teorías democráticas participativas (deliberativas). Una investigación-reflexión”, cuyo investigador responsable es Raúl Villarroel. 


\section{Desarrollo ético y deliberación democrática}

En un artículo anterior, publicado en Revista de Filosofía ${ }^{2}$, y con el propósito de establecer una vinculación teórica entre las nociones de desarrollo, democracia y ciudadanía, tuve en cuenta las ideas de varios pensadores actuales (Denis Goulet, David Crocker, Amartya Sen, Martha Nussbaum y otros) que han reflexionado al respecto y se han planteado de manera crítica frente a los fines y medios que definen actualmente los cambios sociales, económicos y culturales producidos en los países y regiones más o menos pobres del mundo. Examiné en ese escrito lo que podría considerarse como el rasgo más distintivo de su reflexión. Dicho sucintamente, este consiste en proponer una ampliación crítica del perfil puramente economicista y tecnocientífico con que el fenómeno del desarrollo se entiende en la actualidad. Para ello, estos autores estiman necesario abordar las causas de la desigualdad global, el hambre, la pobreza y la serie de otros problemas vinculados, con una concepción explícitamente basada en principios éticos. Se plantean de modo crítico respecto de aquellos enfoques principalmente cuantitativos del desarrollo - que lo han entendido en términos de puro crecimiento económico-, incorporando elementos de orden más bien cualitativo para su definición. Estos últimos derivan de una reflexión vinculada a las capacidades y libertades de los individuos, a los procesos de modernización social y a otros asuntos concomitantes con ellos. De este modo - piensan-, las personas podrían generar las "capacidades" necesarias que les permitan alcanzar realizaciones satisfactorias y vivir el tipo de vida que ellas mismas consideran más valioso (Sen 1998). Sus diversos planteamientos coinciden en la necesidad de enfatizar éticamente tanto los estudios como la formulación de políticas y las prácticas concretas concernientes al desarrollo presente y futuro (Crocker 2008), para reducir y superar las situaciones de pobreza, desigualdad, violencia, degradación ambiental y exclusión que afectan a las personas en el mundo. Adoptada esta visión ampliada del desarrollo, éste ya no se ve asociado y medido únicamente por el crecimiento del Producto Interno Bruto, sino como una expresión de las capacidades humanas para llevar una vida más libre y más digna (Sen 1998, 2000a, 2000b).

No obstante, de todo aquello se debe inferir que, para que un cambio de esta naturaleza se pueda materializar, es necesario pensar (así como lo han hecho de diverso modo autores como Crawford Macpherson, Jürgen Habermas, John Rawls, Carlos S. Nino, Jon Elster, Seyla Benhabib y otros) en el establecimiento de una estructura democrática mayormente participativa, que, estimulando socialmente la preocupación por los problemas colectivos, aumente la eficacia política y contribuya a formar una ciudadanía capaz de interesarse de manera continuada por el proceso del gobierno. Vale decir, es necesario pensar más allá de la línea de pensamiento de cuño liberal, que ha defendido la necesidad de restringir la participación política de los ciudadanos y que

$2 \quad$ Villarroel R. (2013) "Ética del desarrollo, Democracia deliberativa y Ciudadanía biológica. Una articulación en clave biopolítica afirmativa", en Revista de Filosofía, Vol. LXIX 
ha querido remitir la gestión de los asuntos públicos a la gestión de unas élites elegidas en elecciones libres por los ciudadanos (Pérez-Zafrilla 2010, p. 166). Es esta limitación de la participación de los ciudadanos en los asuntos públicos la causa de que se haya desencadenado el fenómeno tan conocido y masificado de apatía y distanciamiento respecto de la política. Ello también ha incidido poderosamente en el viraje egoísta del carácter de la política, por cuya actividad solo se busca la reducción de los intereses privados en conflicto (ibíd.).

En un interesante artículo publicado en el volumen colectivo titulado Democracia, ¿en qué estado?, la politóloga estadounidense Wendy Brown comenta esta fusión entre poderes, haciendo énfasis en el hecho de que no siendo un proceso reciente aquel por el cual la influencia de los grandes grupos de poder socava las esperanzas y las prácticas del poder ciudadano, éste ha alcanzado un nivel sin precedentes. Al respecto señala: "No se trata simplemente de grupos que compran a los políticos y modelan abiertamente la política nacional y extranjera, ni de que los medios de comunicación que les pertenecen ridiculicen la idea misma de información pública y de responsabilidad del poder. Más que una interferencia, las grandes democracias son testigos de una fusión del poder de los grupos y el poder del Estado. [...] El demos no es capaz de ver lo que hay detrás de la mayoría de estos desarrollos, y menos aún de cuestionarlos, de oponérseles y proponer otros objetivos" (Brown 2010, p. 55).

Podríamos suponer, entonces, que esta primacía del interés privado, que consagra la democracia liberal, está en abierta oposición a la concepción más clásica de la democracia y repercute en la deflación ostensible de la participación ciudadana en la actividad política, por lo que la toma de decisiones concernientes a los bienes públicos queda remitida a la actividad de una particular clase de expertos profesionales, la clase de los políticos, que subrogan -en nombre de la ciudadanía- la titularidad de sus derechos a propósito de dichas decisiones (Barber 2004, pp. 394-395). Se puede recordar en tal sentido el modelo de democracia elitista propuesto, por ejemplo, por Schumpeter y sus muchos sucesores, en que la democracia es vista como una competencia entre élites y donde la gente común tiene algo que decir solo en época de elecciones, para conferir a estas élites el derecho de gobernar y legislar. En tal caso, se podría hablar, entonces, de una "ciudadanía de baja intensidad", que está debilitada en su fuero y en su protección jurídica, y se ve impedida del recurso a espacios colectivos, independientes y basados en la solidaridad (Gudynas 2009). Por cierto, la reclusión del individuo en la esfera de su privacidad constituye el resultado último de la operación democrático liberal, con lo cual termina por anularse el principio social de la cooperación intersubjetiva ciudadana, cuyo fomento y desarrollo finalmente parece ser una tarea completamente ajena al Estado y al gobierno.

Por ello, se requeriría una participación directa de los ciudadanos en las instituciones clave del sistema político, en los lugares de trabajo y en la comunidad local. Democracia, en otras palabras, no es solo la toma de decisiones a través de la simple suma de las preferencias electorales, sino aquello que ocurre como resultado de los procesos de reflexión, generación y transformación de las preferencias mediante un diálogo informado y respetuoso de las diferencias (Dryzek 2013). De este modo, en nuestra época parece necesario aumentar los recursos cívicos de los grupos de base 
ciudadana y disminuir el poder burocrático no responsable de sus propias decisiones, al que no parecen inquietarles las implicancias sociales lesivas de sus determinaciones. Ello implicaría un robustecimiento y una expansión de esa potencia ciudadana. Se trataría de volverla capaz de hacer frente de manera crítica -y en vistas de su efectivo cumplimiento-a la promesa igualitaria incumplida de las democracias modernas liberales y a la abdicación que el Estado - por causa de la racionalidad política neoliberal que lo ha subsumido- ha hecho de su papel regulador, desviando o dejando de lado con facilidad su responsabilidad y la atención a sus propios principios fundantes.

Como es muy evidente, la noción de "ciudadanía" ha adquirido una relevancia significativa durante las últimas décadas en la filosofía política. Existirían dos razones fundamentales para ello (Peña 2003, p. 215). Por un lado, la necesidad de hacer compatible la condición legal de ciudadano con la pluralidad de identidades colectivas que caracteriza a las sociedades democráticas. Por otro lado, la constatación de que la concepción liberal dominante de la ciudadanía adolece de un déficit democrático que impide afrontar diversos problemas relacionados con el interés común.

Cabe recordar, de paso, que esta última circunstancia es en buena medida también un efecto de la orientación doctrinaria provista por el conocido informe The Crisis of Democracy. Report on the Governability of Democracies to the Trilateral Commission $^{3}$, elaborado por Michael J. Crozier, Samuel P. Huntington y Joji Watanuki en 1975, referido al fenómeno de la disfuncionalidad e ingobernabilidad que comenzó a afectar a las democracias como consecuencia de los problemas ocasionados por un aumento de las demandas sociales, frente a una capacidad financiera e institucional que se mantenían constantes, cuando no decrecientes. Como se sabe, según los autores del informe, la crisis que afecta a los sistemas democráticos deja en evidencia la existencia de un "exceso de democracia" o un "exceso de participación ciudadana", manifiesta en el incremento de las expectativas sociales de los ciudadanos. El informe señala al respecto: "En años recientes, las operaciones del sistema democrático parecen efectivamente haber generado un quiebre de los medios de control social, una deslegitimación de la política y otras formas de autoridad y una sobrecarga de las demandas sobre el gobierno, excediendo su capacidad para responder (ibíd., p. 8) y "Las demandas sobre el gobierno democrático crecen, mientras la capacidad del gobierno democrático se estanca” (ibíd., p. 9). Ello provoca una importante sensación de frustración e incomodidad ciudadana, lo que tarde o temprano termina revirtiéndose sobre el propio gobierno.

El conflicto suscitado, entonces, se debería a que el sistema político-administrativo de las democracias tradicionales estaría superado por el acelerado progreso de la

3 El Informe señala: "La Comisión Trilateral se formó en 1973 por ciudadanos particulares de Europa occidental, Japón y Norteamérica, para favorecer la cooperación cercana entre estas tres regiones respecto de problemas comunes. Busca incrementar la comprensión pública de estos problemas, apoyar propósitos de manejo conjunto e inculcar hábitos y prácticas de trabajo conjunto entre estas tres regiones". La Comisión Trilateral estuvo dirigida inicialmente por el politólogo estadounidense de origen polaco Zbigniew Brzezinski, quien fuera asesor en materias de seguridad nacional del presidente Jimmy Carter. 
tecnología y la complejización de la estructura social. En razón de ello, cabría esperar que una mayor participación ciudadana tornara finalmente ingobernable al Estado, por lo que parece indispensable tecnocratizar al gobierno, entregando la conducción de los asuntos públicos a otras instancias distintas de aquellas políticas tradicionales: asociaciones, instituciones, empresas y otros, que en representación de los distintos grupos de interés puedan alcanzar con mayor facilidad los acuerdos y la resolución de las diferencias entre los actores sociales (Crozier, Huntington \& Watanuki 1975).

El problema es que las desigualdades sociales y económicas generadas como consecuencia de semejante abandono comprometen el estatuto esencial de la ciudadanía. Se traducen, efectivamente, no solo en la pérdida de los derechos - a la asistencia social o a la provisión estatal de los servicios-, sino en la eliminación efectiva de la participación en los asuntos públicos. De tal modo, directa o indirectamente, terminan por desembocar en exclusión política y en la pérdida de legítimos reconocimientos. En nuestros días, dicha circunstancia parece propiciar la emergencia de un conjunto de planteamientos políticos asociados al restablecimiento del protagonismo ciudadano. Reiterando, por las razones anteriormente señaladas, la noción de ciudadanía ha adquirido una marcada relevancia en las discusiones de la filosofía política contemporánea. Ciertamente, parecen haberse hecho visibles nuevas expresiones y modalidades de ciudadanía activa, expresadas a través de la reivindicación de algunos derechos aún no reconocidos, que pugnan por ser integrados en las estructuras sociales, jurídicas, económicas y culturales de las sociedades contemporáneas.

\section{Ciudadanía ambiental}

Habida cuenta de lo afirmado, entonces, y a modo de extensión reflexiva de lo señalado en el artículo mencionado en líneas iniciales, me propongo ahora profundizar el examen de la noción de "ciudadanía", que ya presenté anteriormente a partir de su expresión "biológica" en el artículo señalado en un comienzo; claro que esta vez en su manifestación "ambiental", es decir, intentaré ahora un examen de la ciudadanía que esté acometido a partir del contexto teórico desplegado por la problemática ecológica, teniendo en cuenta las determinaciones y desafíos que impone a la figura de la ciudadanía la supuesta existencia de un fenómeno de devastación antropogénica como el que se sostiene que afecta al planeta en nuestros días. Intentaré, a continuación, esbozar algunas consideraciones que permitan el avance de esta reflexión particular, considerando que la literatura filosófico-política contemporánea presenta variados alcances teóricos que podrían ser atendidos en este sentido, puesto que ellos también buscan ampliar el concepto canónico de ciudadanía presentado inicialmente por Marshall y referido solo a aquellos derechos sociales que otorgan el estatuto ciudadano a los individuos.

Durante el último tiempo, una vasta literatura internacional e interdisciplinaria respecto del asunto de la "ciudadanía ambiental" ha venido a refrescar los debates acerca de la relación entre ecología y democracia, así como a redefinir la preocupación por aquellas determinaciones sociopolíticas que resultan indispensables para el desarrollo 
sostenible (Latta y Wittman 2010). Estos debates han implicado una discusión respecto de la falta de continuidad entre las relaciones ecológicas y las fronteras políticas, y han enfatizado la necesidad de reinventar la perspectiva y el alcance de la ciudadanía, sobre todo en lo que dice relación con la conciencia de los sujetos sociales y con las relaciones políticas y territoriales formales. Así ha sido tematizado el asunto, por ejemplo, por Andrew Dobson (2003), Eduardo Gudynas (2009) o Elizabeth Jelin (2000). Esta literatura ha analizado también las implicaciones de las diferentes tradiciones políticas (liberal, republicana, comunitaria) en cuanto a la forma en que la naturaleza se articula con la esfera política a través los derechos de participación ciudadana, las responsabilidades y la deliberación, como, por ejemplo, se le encuentra en John Barry (2000), Derek Bell (2005), Andrew Dobson (2003), o Mark Smith (1998).

En este sentido, el intento de vincular la cuestión de la ciudadanía con el problema de la crisis del entorno natural ha admitido variadas formas de denominación, tales como "ciudadanía ambiental", "ciudadanía verde", "ciudadanía ecológica" o "ciudadanía ambiental global", las que han sido utilizadas de diversa manera por los teóricos preocupados del problema. Entre otras aproximaciones al tema, destaca el planteamiento del inglés Andrew Dobson, quien, desde la perspectiva de la filosofía política, ha propuesto un enfoque en el que adquiere relevancia el asunto de los derechos y los deberes concernientes al ordenamiento democrático del estado liberal moderno (Dobson 2005). Buscando distinguir entre una "ciudadanía ecológica" y una "ciudadanía ambiental", caracteriza a esta última como aquella que se expresa en términos de derechos ambientales y que se ejerce, en consecuencia, en la esfera pública; siendo sus principales virtudes aquellas de la razonabilidad y de la voluntad dialógica para aceptar los argumentos más convincentes. En tal sentido, la ciudadanía ambiental estaría referida a las configuraciones políticas determinadas por el Estado-nación y correspondería a "los intentos de extender el discurso y la práctica de la exigencia de derechos al contexto ambiental" (Dobson 2005, p. 48). La ciudadanía ecológica, por otra parte, se ocuparía de ciertos deberes cuya naturaleza no es contractual y operaría mediante el lenguaje de la virtud, siendo explícitamente no-territorial. Dobson señala que esta ciudadanía ecológica contendría las virtudes típicamente asociadas a la tradición del liberalismo como así también a la del republicanismo cívico; "la primera la encontramos en su referencia a la virtud de «estar abiertos al debate y la deliberación»", mientras que el republicanismo cívico "se expresa en la idea de que «alcanzar la sostenibilidad es una empresa colectiva»" (Dobson 2005, p. 58), lo que constituye claramente una particular expresión de la idea del "bien común". Antes que contradecirse, Dobson ve que más bien ambas se pueden complementar y favorecer por medio de su conjunción el logro de una sociedad sostenible.

Pero, ¿qué es lo que ha de entenderse entonces por “ciudadanía ambiental”, más precisamente y en este mismo sentido? En primer lugar, que la ciudadanía ambiental implica el reconocimiento de que el interés particular no siempre protege o mantiene los bienes públicos, que es lo que ocurre, por ejemplo, cuando lo que está en juego es la protección del medio ambiente. Se trata de refutar la socorrida creencia de los economistas que a menudo han argumentado que el problema con los recursos naturales de propiedad pública es que dan lugar a lo que llaman "externalidades de mercado", 
debido al hecho de que la inexistencia de derechos privados de propiedad respecto de ellos desincentivaría su efectiva protección y, por lo mismo, conduciría inevitablemente a su ruina, razón por la cual lo que corresponde es privatizarlos, en vistas de su mejor conservación. No obstante, ante semejante argumentación, se puede pensar también que el motivo del beneficio implicado en la posesión privada de los bienes naturales mal podría no alentar su destrucción, sobre todo cuando los dueños de un "recurso" natural renovable y frágil vean en él la alta rentabilidad derivable de su sobreexplotación con fines comerciales y la reinversión posterior del provecho económico obtenido en otros emprendimientos tanto o más lucrativos, lo cual implicaría inevitablemente su aniquilamiento definitivo (Norton 2000, p. 36). Ello permite postular, luego, que la propiedad privada no es suficiente para la protección de los bienes ambientales, como a algunos les gusta afirmar, recurriendo a tales razones discutibles o engañosas. Asumir que la propiedad privada es la única solución para la protección de los bienes naturales es también ignorar el éxito histórico de aquellos sistemas creados por las sociedades tradicionales para protegerlos por muchas generaciones. Por lo tanto, se podría concluir que los derechos de propiedad no son ni suficientes ni necesarios para asegurar la protección de dichos bienes. El famoso episodio de la "tragedia de los comunes" de Garret Hardin ya ha constituido una fuente de inspiración notable para todo tipo de inferencias con respecto al problema del empleo racional -pero egoísta- de los bienes natrales (Hardin 1968). De acuerdo con lo dicho, entonces, una ciudadanía de tipo ambiental tendría que establecer un compromiso decidido con el bien común antes que con los intereses particulares de los individuos. Al ciudadano ambiental le preocuparía ese enfoque constante en soluciones de tipo egoísta dadas a los problemas ambientales, porque estas implicarían el riesgo de inhibir la posibilidad de encontrar e implementar mejores soluciones de tipo colectivo, de soluciones tendientes al bien común.

La ciudadanía ambiental, al mismo tiempo, implicaría la idea de que los deberes hacia el medio ambiente se derivan de derechos ambientales, entendidos estos como una cuestión de justicia natural. Ello, porque la ciudadanía siempre ha sido una cuestión de balance entre derechos y deberes (Dobson 2007). Históricamente, el concepto liberal de ciudadanía se ha centrado en los derechos de los ciudadanos -el derecho a voto, el derecho a la seguridad social y otros. Y si bien los deberes han tenido lugar en la ciudadanía liberal, ellos no han jugado un papel de gran importancia. El concepto republicano de ciudadanía, en cambio, ha centrado su atención en las responsabilidades que tienen los ciudadanos con respecto al colectivo social al que pertenecen. Es decir, aunque los ciudadanos republicanos reconocen y valoran sus derechos, estos son menos importantes para ellos que lo que lo son sus responsabilidades o deberes. En este contexto, evidentemente habría que considerar a la ciudadanía ambiental mucho más compatible con el esquema republicano de ciudadanía que con el esquema liberal. Por razones obvias, los ciudadanos del medio ambiente tienen la responsabilidad de trabajar por una sociedad sostenible, y esto abarca todas las actividades que se pueden considerar como normales y consabidas en relación con una ajustada ciudadanía ambiental, entre las cuales están, obviamente, reciclar, reutilizar y conservar. Sin embargo, el asunto clave aquí es recordar que el ejercicio de la ciudadanía es una actividad que siempre conlleva públicas implicaciones y por lo mismo induce el reconocimiento de deberes 
para con los demás. Sobre todo, desde un punto de vista ambiental, donde hasta el más mínimo acto, por imperceptible o insignificante que nos parezca, tiene repercusiones e impacto público difícil de dimensionar. "En la medida en que vivimos nuestra vida, requerimos de recursos ambientales, y dejamos residuos ambientales. Como animales humanos que somos, eso es inevitable" (ibíd., p. 281). La consideración de este solo hecho nos recuerda aquella ya antigua metáfora de la "línea de flotación" (Plimsoll line) propuesta por Herman Daly en 1991 para pensar en torno de la capacidad de carga a la que puede ser expuesto el planeta por causa de las actividades industriales y productivas. Por una vía analógica, Daly introdujo la posibilidad de pensar críticamente que, así como la línea pintada en los costados de una embarcación nos advierte de hasta dónde esta puede ser ocupada sin correr el riesgo de naufragar, asimismo debiéramos tener en cuenta que la racionalidad económica imperante sobrecarga esta embarcación en la que todos vamos navegando, que es el planeta Tierra - de modo de aumentar la eficiencia y la rentabilidad del transporte-, pero sin considerar las características físicas de la nave, terminando por provocarle un impacto de consecuencias impredecibles en tanto por ello se llegan a superar los límites dentro de los cuales la carga puede ser manejada de forma segura (Daly 1991). En este caso, y siguiendo la figuración retorica de Daly, se requeriría de un reglamento que protegiera a los marineros del colapso provocado por las fuerzas económicas ingobernables.

Por ello, parece preciso admitir que como humanidad enfrentamos serios problemas con respecto a la materialización efectiva de una sociedad sostenible hoy en día-seguiremos enfrentándolos en el futuro próximo o lejano, claro está. Y considerando que hasta la fecha los argumentos éticos, estéticos, religiosos y económicos para la conservación y protección del medio natural surgidos en el contexto de las sociedades liberales de nuestro tiempo han avanzado relativamente poco, parece necesario atender a otro enfoque analítico respecto del problema y evaluar su eventual influencia política y su capacidad para motivar la acción ciudadana, pensando en que una actitud comprometida de los individuos con la crisis ambiental, amparada en un marco amplio de derechos y deberes, constituiría un elemento clave a la hora de disponer un curso de acción más efectivo que el que hasta ahora se ha seguido en el enfrentamiento de la situación.

En este sentido, se podría aludir a una variante teórica de esta gran reflexión sobre la ciudadanía ambiental, correspondiente a lo que algunos autores han llamado el enfoque de los derechos humanos (Brei 2013) y que constituye un intento de abordaje de las cuestiones ambientales a través del lenguaje y la teoría de los derechos legales y morales. Existiría, al menos un par de razones para suponer que mirar el asunto de la crisis ambiental desde la perspectiva de los derechos humanos pueda resultar plausible teóricamente. Hay, por cierto, una particular simetría que es posible establecer entre los problemas ambientales, que afectan a toda la humanidad en el planeta (por ejemplo, el cambio climático), y los derechos humanos, que tienen una extensión universal pues se aplican a problemas que afectan todos los seres humanos. Esta misma posible simetría se daría también cuando se observa que tanto los problemas del medio ambiente como los de los derechos humanos trascienden las fronteras políticas (ibíd., p. 394). El caso es que todos los intentos de hacer frente a los problemas ambientales en el nivel simplemente local, incluso nacional, pueden resultar ineficaces ya que el asunto es a 
estas alturas de extensión decididamente global. Incluso, podríamos decir que es hasta transhistórico, si admitimos que la ciudadanía ambiental es un asunto tanto internacional como intergeneracional (tal vez hasta interespecífico, se podría agregar) (Dobson 2003, pp. 21-30, 78-81). Entonces, enfrentar este tipo de dificultades considerando que está en juego el futuro de las personas -las presentes y también aquellas que aun no les resulta posible comparecer ante nuestras decisiones hoy, pero que seguramente de tener la oportunidad de hacerlo no aprobarían muchas de nuestras actuales opcionespermite pensar que los así llamados "derechos de tercera generación", entre los que cabe mencionar el derecho a un medio ambiente no destruido -derechos que aunque exigibles a los Estados, no son materializables sino a través de la activa participación de los ciudadanos-, constituyen imperativos legales y morales estrictos que encarnan apreciadas normas y valoraciones sociales en el mundo contemporáneo (Brei 2013, p. 394). Por tanto, parece razonable suponer que entre los imperativos y normas reflejadas por los derechos humanos aquellos que remiten a nuestra relaciones con el medio ambiente natural y a los efectos que ellas tienen sobre éste sean algo decisivo que concierne a nuestro más puro interés ciudadano.

Es de vital importancia, entonces, entender que los deberes ciudadanos hacia el medio ambiente no constituyen un asunto de caridad o simple buena voluntad sino de pura justicia. Por lo mismo, como señala Dobson a modo de ilustración, nuestras responsabilidades respecto de la destrucción ambiental en curso difieren de aquellas que habríamos tenido hacia las victimas del Tsunami de 2004 en el Océano Índico -o las del terremoto de Chile del 2010- porque somos al menos en parte responsables de la primera, y de ninguna manera de la segunda (Dobson 2007, p. 281). En el caso del sufrimiento del que no somos responsables, la caridad y la compasión parecen ser las respuestas más adecuadas. En el caso del sufrimiento del que sí lo somos, la única respuesta adecuada es la justicia; algo que suena muy coincidente con la kantiana distinción entre deberes perfectos e imperfectos. Esto mismo hace que reparar el daño ambiental producido, minimizarlo en su expresión, contenerlo en sus alcances o anticiparlo para impedir su ocurrencia, constituya una cuestión que va más allá de la simple modificación de nuestros actuales estilos de vida. Aunque nos parezca que ello es un elemento clave de cualquier posible intento de solución de este problema, porque en verdad se trata de un cambio profundo de aquellas estructuras institucionales que permiten y reproducen la injusticia contenida en la destrucción del entorno natural, entre las cuales, precisamente, se encuentra una muy restringida y fútil comprensión del problema de la ciudadanía y las prácticas ciudadanas, que ha jugado históricamente un rol determinante en el recrudecimiento de la situación.

A propósito de todo esto, y buscando traer esta reflexión a un terreno más cercano, vinculado con nuestra contingencia nacional y regional - definida por la diversidad cultural derivada de sus múltiples cosmovisiones indígenas y una historia compartida de conflictos políticos-, parece importante también considerar aquí la realidad del debate medioambiental y ciudadano en América Latina. Este se relaciona tanto con los problemas y quiebres sociales derivados del proceso de modernización como con los efectos y transformaciones profundas que el fenómeno de la globalización ha producido. Y pese a que esta discusión aún no consigue asentar un estatuto teórico específico en 
el discurso académico local, puesto que no ha logrado poner en visibilidad un factor diferencial que la perfile y distinga de la reflexión llevada a cabo al respecto en los países del primer mundo ${ }^{4}$, igualmente se ha convertido en un asunto de constante preocupación para los investigadores. Incluso, ha trascendido al ámbito público y ha dado lugar a manifestaciones de protesta política de diverso signo en los distintos países de la región (Latta y Wittman 2010, p. 107). Ello ha propiciado que, durante el último tiempo, se haya vigorizado la atención prestada en esos debates al asunto general de la ciudadanía por parte de los expertos; en tanto el tema específico de la ciudadanía ambiental cobra cada vez más relevancia en los planteamientos y exigencias políticas de los diferentes grupos de interés.

Se podría señalar, según lo demuestra la investigación, que una relación indisoluble entre políticas de la tierra, sentido de la vida e identidad colectiva sustenta la lucha de los pueblos originarios latinoamericanos por el reconocimiento político y por la ampliación de su capacidad de agencia social (Latta 2007a; 2009); o que las nuevas tendencias políticas que impulsan el fortalecimiento de la democratización y las reformas institucionales en la región incluyen una atención primordial a la cuestiones de la gobernanza ambiental. Asimismo, los esfuerzos por salvaguardar la supervivencia de los bienes naturales específicos, como por ejemplo el agua, han vinculado las luchas de estos recursos con el robustecimiento de la acción ciudadana. Ilustrativo resulta en este sentido el movimiento de resistencia organizado legalmente por la comunidad local frente a la operación minera de gran escala emprendida hace pocos años por el consorcio internacional Barrick Gold en el valle del Huasco, en la cuarta región de Chile, para la explotación del yacimiento Pascua Lama. Las agrupaciones de ciudadanos organizados, como se sabe, sostuvieron argumentos ambientalistas para oponerse a dicha intervención señalando que el proyecto afectaría el suministro de agua de los casi 70.000 parceleros del lugar, puesto que contaminaría letalmente el curso fluvial del valle con cianuro, ácido sulfúrico y mercurio, entre otros compuestos químicos letales.

Este ejemplo pone en evidencia que en el contexto latinoamericano las cuestiones ambientales están profundamente ligadas a los problemas de la vida social, a los fenómenos

$4 \quad$ Latta y Wittman (2010) afirman que América Latina es el hogar de culturas políticas informadas por una amplia gama de influencias, incluyendo las tradiciones europeas, como el republicanismo, el liberalismo y el marxismo, y las tradiciones sociales y políticas regionales, como la de la Revolución bolivariana y la pedagogía de los oprimidos de Paulo Freire. Además, existiría una larga tradición de instituciones socio-políticas indígenas, desde los usos y costumbres de los mayas a la del Admapu del pueblo mapuche. Cada una de estas diversas tradiciones políticas está incrustada en las visiones específicas de las relaciones socio-ecológicas latinoamericanas; desde las instituciones del liberalismo de la propiedad privada a las del cultivo vinculado al respeto por la Pachamama propias de la organización social quechua. Estas herencias político-ecológicas son constantemente reinventadas y vueltas a combinar, como en los municipios autónomos zapatistas de México, en el Movimiento de los Sin Tierra del Brasil, y la recuperación indígena del Estado en Bolivia (op. cit., p. 109). Creemos que todo ello puede explicar la singularidad de la realidad cultural latinoamericana, difícil de tamizar en vistas de su definición exacta y distintiva. 
de marginación e injusticia tanto cultural como económica; lo que permite constatar que en esta región del mundo, como en otras semejantes, la condición ciudadana no es una categoría obvia o inherente a la subjetividad social; y que la demanda de los derechos ambientales es, al mismo tiempo, una de las expresiones más determinantes de las luchas por el reconocimiento y la inclusión social. Porque, cuando la legislación existente ampara operaciones extractivas mineras que ciertamente ponen en riesgo la salud de la población y arremeten en contra de los bienes naturales no renovables en vistas de un provecho privado, es claro que los afectados por la norma legal no han sido reconocidos en su capacidad de agenciamiento del espacio geográfico en que se han asentado y su condición ciudadana les ha sido absolutamente restringida.

\section{Conclusión}

Ahora bien, para terminar, si se sigue de manera general el espíritu de esta reflexión, se debiera convenir en que parece necesario avanzar sobre el diseño de un modelo de compromiso ciudadano, que no surge de la pertenencia a una comunidad política determinada, sino más bien de la situación de desigualdad generalizada y de la explotación de una parte de la población mundial que caracteriza a la economía globalizada contemporánea, que seguirá operando como un juego de suma cero, de ganadores y perdedores, a menos que se desplieguen sistemáticos esfuerzos por redistribuir la riqueza. Es, de hecho, la minoría de los ciudadanos de los países industrializados la que actualmente depreda de manera más significativa el entorno natural. Con una lógica implacable, opera a través de diversas formas de explotación de los bienes naturales y del territorio. Por lo mismo, se podría pensar que le debe a la mayoría del mundo una forma de ciudadanía ambiental, que incluye una fuerte dosis de justicia redistributiva.

Es muy claro, que una "política de la vida" (Rose 2000, p. 1396) -de la ecología, de los propios estilos de vida, de la identidad cultural personal y colectiva- debe emerger vigorosamente en nuestro tiempo, para unir y transversalizar los valores de la emancipación y la justicia social. Puesto que los ciudadanos han perdido la fe en las prácticas de la gubernamentalidad neoliberal, una subpolítica debe comenzar a desafiar a las esferas convencionales de la política y del tradicional "gobierno de los hombres", como diría Michel Foucault. El presente -y el futuro- se estructuran en torno de la centralidad de los problemas del riesgo y la concomitante necesidad de surgimiento de políticas medioambientales capaces de enfrentar la crítica situación del tiempo presente. A la par, un nuevo tipo de subjetividad tiene que constituirse en función de la respuesta requerida para esta acuciante demanda y comenzar a dar a la política una fisonomía renovada, desde un nuevo sentido de la autonomía personal, donde la experiencia individual no acontece a partir de la atomización y el aislamiento sino en la plena integración ciudadana; entendiendo la ciudadanía no como la mera pertenencia a la sociedad o al colectivo nacional sino como la vinculación organizada al tejido social y al medioambiente natural. Pues, como sostiene Rose, es desde estas pertenencias que los individuos autónomos conciben sus aspiraciones y producen 
recíproca y cooperativamente los lineamientos para la práctica de su libertad (Rose 2000, p. 1398).

El esfuerzo por vincular la ecología con la justicia social en el contexto del desarrollo y el fortalecimiento de una noción asentada de "ciudadanía ambiental" puede llegar a proporcionar nuevas herramientas para reflexionar sobre un futuro más equitativo y sostenible. La noción de "ciudadanía ambiental" puede muy bien estar referida también al tema de la "biolegitimidad", que es la forma de reconocimiento social de la vida como "bien supremo" (Fassin 2007); en este caso, de todas las formas de la vida, que son reivindicadas políticamente mediante el ejercicio de los derechos de ciudadanía. Extender las fronteras del diálogo ciudadano para debatir sobre el problema de una mejor gobernanza ambiental constituye un camino de acción colectiva en procura del establecimiento de una ciudadanía ambiental global. Pero, en este punto, es necesario poner atención al hecho de que el problema se hace particularmente problemático en América Latina, sobre todo debido a las limitaciones institucionales existentes, que hasta la fecha no han conseguido incorporar de una manera satisfactoria la dimensión ecológica de las relaciones sociales en la vida política, conforme a una noción de ciudadanía ambiental como la que aquí hemos tratado de delinear en sus caracteres definitorios básicos, y que busca sobrepasar las limitaciones del concepto clásico de ciudadanía propuesto por Marshall.

Hay autores (Gudynas 2009) que piensan que dicha noción tradicional, propiamente occidental, de algún modo colisionaría con el sustrato cultural propio de nuestra región, y deslegitimaría o subordinaría a los distintos corpus de conocimiento socio-ecológicos de los pueblos originarios de la región, lo que obligaría a un esfuerzo mayor de pensamiento para producir una redefinición de la noción en vistas de su mejor ajustamiento conceptual a la realidad cultural y a las concepciones ambientales específicamente latinoamericanas. Parece razonable un planteamiento como el de Eduardo Gudynas, atendida la circunstancia de que la actual coyuntura social, política y cultural de América Latina exige que el vinculo entre medio ambiente y ciudadanía sea concebido de una manera más amplia, no solo constreñido por la cuestión de los derechos y deberes existentes al interior de las fronteras políticas formales.

No obstante, ello trae consigo una dificultad reflexiva no sencilla de esclarecer y que tiene que ver con la aspiración global de la ciudadanía ambiental, con la pretensión de no restringir tampoco a un espacio territorial o geográfico el compromiso activo de los ciudadanos, sino a responsabilidades que se entienden como de alcance planetario, algo que no se identifica tampoco con la mera ciudadanía del mundo o cosmopolita, como es aquello de lo que alguna vez en un sentido semejante nos habló Kant, porque incluye a la comunidad biótica en la comunidad de pertenencia del ciudadano.

Se debe admitir, en todo caso, que una perspectiva como la de la ciudadanía ambiental plantea no solamente estas sino que a la vez muchas otras enormes interrogantes más -que aquí no abordaré porque las considero tareas reflexivas futuras-, entre las cuales estarían, por ejemplo, aquellas que refieren a la fundamentación ética que permitiría justificar el reconocimiento de deberes efectivos hacia-o en relación con- las generaciones futuras y las entidades no humanas. Aún más, si se tiene en cuenta que 
dichos deberes deberían ser reconocidos universalmente para poder ser plasmados en derechos correlativos o en medidas internacionales de respeto y protección coherentes con los mismos. Ya habrá oportunidad para revisar estas interesantes cuestiones éticas y políticas.

\section{Referencias bibliográficas}

Crozier, M.; S. Huntington y J. Watanuki (1975), The Crisis of Democracy. Report on the Governability of Democracies to the Trilateral Commission. New York: New York University Press.

Barber, B. (2004), Democracia fuerte. Córdoba: Almuzara.

Barry, J. (2000), Rethinking Green Politics: Nature, Virtue and Progress. London: Sage.

Bell, D. R. (2005), “Liberal Environmental Citizenship”. Environmental Politics, Vol. 14: $179-194$.

Brei, A. T. (2013), "Rights \& Nature. Approaching Environmental Issues by Way of Human Rights". Journal of Agriculture \& Environmental Ethics 26: 393-408.

Brown, W. (2010), "Hoy en día, somos todos demócratas", en Democracia, ¿en qué estado?, Agamben, G.; Badiou, A.; Bensaïd, D. et al. Buenos Aires: Prometeo libros.

Crocker, D. (2008), Ethics of global development: Agency, capability, and deliberative democracy. Cambridge: Cambridge University Press.

Daly, H. E. (1991), "Elements of Environmental Macroeconomics", en Costanza, R. (ed.), Ecological Economics: The Science and Management of Sustainability, New York: Columbia University Press.

Dobson, A. (2003), Citizenship and the Environment. Oxford: Oxford University Press.

(2005), "Ciudadanía ecológica", en ISEGORÍA. Revista de Filosofía Moral y Política $\mathrm{N}^{\mathrm{o}}$ 32, 2005: 47-62.

(2007), "Environmental Citizenship: Towards Sustainable Development", Sustainable Development 15: 276-285.

Dryzek, J. S. (2013), Foundations and frontiers of Deliberative governance. Oxford: Oxford University Press.

Fassin, D. (2007), "Humanitarianism as politics of life", Public Culture 19 (3): 499520.

(2009), "Another politics of life is possible", Theory, Culture and Society 26 (5): 44-60.

Gudynas, E. (2009), “Ciudadanía ambiental y meta-ciudadanías ecológicas. Revisión y alternativas en América Latina", en Reyes, J. and Castro. E. (eds.), Urgencia 
y utopía frente a la crisis de civilización. Guadalajara: Universidad de Guadalajara y Ayuntamiento de Zapopan, pp. 58-101.

Hardin, G. (1968), "The Tragedy of the Commons", Science, Vol. 162, N 3859 : 1243-1248.

Jelin, E. (2000), “Towards a Global Environmental Citizenship", Citizenship Studies, Vol. 4: 47-62.

Latta, L. (2007), "Environmental Citizenship. A model linking ecology with social justice could lead to a more equitable future", Alternatives Journal 33 (1): $18-20$.

(2007a), "Citizenship and the politics of nature: the case of Chile's Alto Bío Bío”, Citizenship Studies, Vol. 11: 229-246.

(2009), "Between Political Worlds: Indigenous Citizenship in Chile's Alto Bío Bío", Latin American and Caribbean Ethnic Studies, Vol. 4: 47-71.

Latta, L. and Wittman, H. (2010), "Environment and Citizenship in Latin America: A New Paradigm for Theory and Practice", European Review of Latin American and Caribbean Studies 89 (October): 107-116.

Norton, B. G. (2000), "Population and Consumption: Environmental Problems as Problems of Scale", Ethics and the Environment 5 (1): 23-45.

Peña, J. (2003), “La ciudadanía”. En A. Arteta, E. García y R. Máiz (eds.) Teoría politica. Poder, Moral, Democracia. Madrid: Alianza, pp. 215-245.

Pérez-Zafrilla, P. J. (2010), "La necesaria rehabilitación del sistema representativo en las propuestas de reforma democrática”, en ISEGORÍA. Revista de Filosofía Moral y Política, No 42 (enero-junio): 165-182.

Rose, N. (2000), "Community, Citizenship ant the Third way", American Behavioral Scientist 43: 1395-1411.

Sen, A. (1998), Sobre ética y economía. Madrid: Alianza. (2000a), Desarrollo y Libertad. Barcelona: Planeta. (2000b), Nuevo examen de la desigualdad. Madrid: Alianza.

Schumpeter, J. A. (1942), Capitalism, Socialism, and Democracy. New York: Harper.

Smith, M. J. (1998), Ecologism: Towards Ecological Citizenship. Minneapolis: University of Minnesota Press. 